\title{
Trabalho por turnos e vida familiar e social: Perspetivas do trabalhador(a) e do cônjuge
}

\author{
Joana Pereira ${ }^{1}$, Isabel Soares Silva ${ }^{1} \&$ José Keating 1 \\ ${ }^{1}$ Escola de Psicologia da Universidade do Minho
}

\begin{abstract}
Resumo: A investigação sobre o impacto do trabalho por turnos na vida familiar e social tende a privilegiar apenas a perspetiva dos trabalhadores, sendo rara a investigação que compara a perspetiva de terceiros. Considerando esta limitação, o presente estudo contempla a perspetiva dos cônjuges de trabalhadores por turnos rotativos na compreensão do impacto do trabalho por turnos em dimensões da vida familiar e social, procurando avaliar se existem diferenças na perceção dos impactos na díade. Participaram no estudo 51 casais. Verificou-se um acordo moderado nas análises de diferenças das díades, no que diz respeito ao impacto do trabalho por turnos. Por outro lado, tendo em conta os diferentes horários de trabalho de cada membro do casal, os resultados mostraram uma diferença significativa, entre os dois grupos de díades, nas correlações entre o ponto de vista do cônjuge e o ponto de vista do trabalhador sobre a dimensão "Vida de Casal".
\end{abstract}

Palavras-chave: Trabalho por turnos; vida social; vida familiar; perspetiva do casal.

Shift work and family and social life: Worker and spouse perspectives. Research on the impact of shift work on family and social life tends to privilege the perspective of workers, being rare the research that compares the perspective of third parties. Considering this limitation, the present study includes the perspective of the spouses of rotating shift workers in the understanding of the impact of shift work on family and social life dimensions, trying to assess whether there are differences in the perception of impacts on the dyad. 51 couples participated in the study. There was a moderate agreement in the analyses of differences of dyads with regard to the impact of shift work. On the other hand, considering the different working hours of each member of the couple, the results showed a significant difference among the two groups of dyads in the correlations between the spouse's point of view and the worker's point of view on the "Life of Couple "dimension.

Keywords: Shift work; social life; family life; couple's perspective.

A evolução para uma sociedade de 24 horas, motivada por fatores como a globalização da economia, a crescente competitividade entre mercados, o desenvolvimento de novas tecnologias ou a expansão dos serviços para a população, introduz alterações significativas no modo de organização do tempo de trabalho (Baker, Ferguson, \& Dawson, 2003; Costa, 2003; Iskra-Golec et al., 2016), sendo que as fronteiras entre o trabalho e os tempos sociais não são mais fixas e rigidamente determinadas pelo dia de trabalho diurno normal (Iskra-Golec et al., 2016). Com efeito, tal processo de mudança deu origem a um número maior de trabalhadores a laborar para além do horário convencional, isto é, horário compreendido entre as 08:00 - 9:00 e as 17:00 - 18:00 de segunda a sexta-feira (Baker et al., 2003; Costa et al., 2004; Dhande \& Sharma, 2011). A semana de trabalho constituída por 8 horas de trabalho diário, 5 dias por semana, deu lugar a dias e semanas de trabalho mais longos (Perrucci et al., 2007).

Neste contexto, ganha relevância o termo trabalho por turnos, o qual, segundo o Código de Trabalho português, é definido como "qualquer organização do trabalho em equipa em que os trabalhadores ocupam sucessivamente os mesmos postos de trabalho, a um determinado ritmo, incluindo o rotativo, contínuo ou descontínuo, podendo executar o trabalho a horas diferentes num dado período

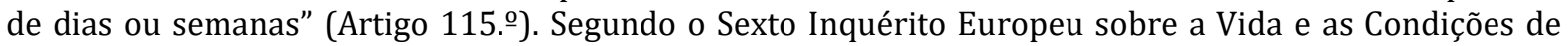
Trabalho, inquérito esse que é realizado de cinco em cinco anos nos países da União Europeia (UE) desde 1991, cerca de $21 \%$ dos trabalhadores referiram trabalhar por turnos no ano de 2015 . Comparativamente com os dados obtidos nos dois períodos anteriores (2005 e 2010), verifica-se um aumento de $4 \%$ (Eurofound, 2016). ${ }^{1}$ Morada para correspondência: Isabel Soares Silva, Escola de Psicologia da Universidade do Minho, Campus de Gualtar, $4710-057$ Braga,
Portugal. E-mail: isilva@psi.uminho.pt 
O impacto do horário de trabalho por turnos estende-se para além do(a) próprio(a) trabalhador(a), interferindo nas suas famílias e meio social. De facto, como referem Baker et al. (2003) a propósito de tal abrangência, a organização do tempo de trabalho pode definir não só a situação financeira, a localização geográfica, o estado de saúde, mas também o nível da interação com a comunidade e a vida familiar. Neste contexto, Newey e Hood (2004) também referem que o impacto do trabalho por turnos pode emergir a um nível multidimensional, podendo traduzir-se, por exemplo, a privações e perturbações de sono (quantidade e qualidade), problemas de saúde (stress) e perturbação da vida social e familiar, perturbação esta que será descrita com mais detalhe no ponto seguinte. Os problemas nas esferas familiar e social tornam-se ainda mais complexos quando os dois membros do casal trabalham e ambos trabalham por turnos, podendo tal combinação representar dificuldades acrescidas, não só nas relações conjugais, mas também nos papéis parentais e na educação dos filhos (Iskra-Golec et al., 2016). Por outro lado, o impacto do trabalho por turnos pode ser sentido de forma diferente dependendo do género, tanto no que diz respeito à vida familiar como à vida social (Craig \& Brown, 2014; Presser, 1994). Por exemplo, no estudo de Craig e Brown (2014), enquanto os homens relatam ver televisão acompanhados da sua parceira como uma atividade de lazer, as mulheres realizam as tarefas domésticas ao mesmo tempo que vêm televisão.

\section{Impacto do trabalho por turnos a nível familiar e social}

Embora o trabalho por turnos seja maioritariamente associado a aspetos negativos, esta modalidade horária pode manifestar-se de forma positiva sobre a vida não-laboral do(a) trabalhador(a) (Iskra-Golec et al., 2017). Alguns autores (e.g., Baker et al., 2003; Costa, 2003, 2016; Silva, 2012; Wilson et al., 2007) identificaram os seguintes aspetos positivos: i) a maior facilidade no acesso a serviços (e.g., ir ao banco ou ir ao médico) cujos horários de funcionamento decorrem similares ao horário de trabalho convencional; ii) compensações a nível monetário (sobretudo majorações económicas associadas a determinados horários de trabalho como o "subsidio de turno"); iii) permitir ao/à trabalhador(a) disponibilizar tempo a meio da semana para as suas atividades de lazer - hobbies; iv) evitar as confusões que os serviços podem ter aos fins de semana; v) dispor de intervalos mais longos de tempo livre, entre os ciclos de mudança de turno; vi) permitir maior flexibilidade na gestão das responsabilidades familiares/domésticas, tendo esta vantagem sido associada particularmente no caso de trabalhadoras por turnos. No contexto do último aspeto identificado, Hossain e Shapiro (1999) mencionam também que o trabalho por turnos pode facilitar gestão no tempo passado com as crianças e na vida doméstica entre os membros do casal, para além de poder satisfazer preferências individuais quanto ao tempo de trabalho.

Numa perspetiva distinta, e de um modo geral dominante na literatura (Silva, 2012), o trabalho por turnos tem sido associado a aspetos negativos da vida conjugal, familiar e social do(a) trabalhador(a) (e.g., Costa, 1997; Costa \& Silva, 2019; Demerouti et al., 2004; Lourenço et al., 2008; Martins \& Martins, 1999; Silva, 2012). 0 aspeto mais destacado na literatura diz respeito à dessincronização entre o tempo de trabalho e o resto da sociedade, onde as atividades sociais e familiares tendem a estar organizadas de acordo com os ritmos orientados para o horário convencional, ou seja, finais de tarde e noite, assim como os fins-de-semana (Costa, 2003; Monk et al., 1996). 0 facto do(a) trabalhador(a) por turnos estar muitas vezes a trabalhar nestes períodos pode conduzir a dificuldades acrescidas na gestão da vida entre o trabalho e a família (Tuttle \& Garr, 2012), sobretudo a nível do relacionamento conjugal, realização de atividades domésticas, encontros intrafamiliares e no relacionamento e educação dos filhos (Iskra-Golec et al., 2017; Lourenço et al., 2008).

No estudo de Greenwood (1983), o principal objetivo foi compreender os possíveis efeitos do sistema de turnos rotativo na qualidade de vida dos trabalhadores, comparando trabalhadores por turnos com trabalhadores diurnos, tendo sido solicitado aos entrevistados para indicarem em que medida lhes eram aplicáveis 14 afirmações sobre a sua vida familiar e social e mencionar a facilidade ou dificuldade de realizar 18 atividades. Os trabalhadores por turnos apontaram como maior dificuldade as atividades que exigiam comprometimento regular (e.g., acompanhar programas de televisão, fazer parte de uma equipa desportiva), manter um relacionamento, seguir interesses pessoais e tempo gasto para atividades com amigos, esposa e filhos. Em comparação com os trabalhadores diurnos, o único aspeto positivo apontado pelos trabalhadores por turnos foi a facilidade em realizar tarefas durante o dia. Apesar da interferência familiar, não foram encontradas quaisquer diferenças na qualidade da vida familiar entre os dois grupos. Em todo o caso, como salienta o próprio autor do estudo, os resultados obtidos apontaram para um elevado grau de isolamento da vida familiar e social por parte do trabalhador por turnos devido aos seus horários de trabalho.

No que diz respeito aos papéis parentais, outros autores (e.g., Li et al., 2014; Volger et al., 1988) verificaram que pais que laboram por turnos apresentam uma menor possibilidade de acompanhamento escolar dos filhos (e.g., trabalhos de casa), comparativamente com os trabalhadores diurnos. Neste 
âmbito, as horas trabalhadas principalmente durante a tarde, parecem exercer um impacto elevado na interação pais - crianças (Rapoport \& Le Bourdais, 2008), embora tal impacto possa diferir de acordo com a idade da criança. Por exemplo, no estudo de Volger et al. (1988), no caso de crianças em idade préescolar, pais que trabalham por turnos quando comparados com pais que trabalham em horário diurno, mostraram mais tempo livre comum com os filhos, mas já em idade escolar a situação invertia-se. Por outro lado, nos períodos em que os trabalhadores por turnos laboram nos turnos da tarde e da noite o tempo comum entre pais e crianças encontra-se reduzido. A nível social, são apontadas interferências na programação de atividades, vida associativa e relações de amizade, assim como o tempo dedicado ao lazer (Prata \& Silva, 2013; Silva et al., 2014). Dhande e Sharma (2011), referem que para além do fim de semana ser apontado como uma ocasião importante para atividades como, por exemplo, recreativas e religiosas, a necessidade de estabilizar o tempo de sono, devido ao cansaço causado pelo trabalho por turnos, também pode ser um fator determinante da interferência no tempo para as atividades sociais. Desta forma, o trabalhador por turnos poderá ter uma participação diminuída nesta esfera importante da vida, o que poderá levar a stress adicional (Baker et al., 2003; Costa, 1997; Martins \& Martins, 1999; Simões et al., 2010; Strazdins et al., 2004). 0 estudo de Craig e Brown (2014), analisou a associação entre o trabalho ao fim de semana e o tempo de lazer partilhado com os parceiros, as crianças e outros (família e amigos). Especificamente, analisou as associações entre o trabalho ao fim de semana e o tempo de lazer partilhado no dia de trabalho no sentido de averiguar se o tempo de lazer partilhado era compensado nos restantes dias da semana seguinte, tendo tal análise sido feita em três tipos de famílias, i) casais com filhos, ii) casais sem filhos e iii) solteiros sem filhos. Os resultados mostraram uma maior associação no lazer partilhado com o cônjuge e com os filhos. Para os casais com filhos, o trabalho ao domingo mostrou uma associação ainda mais negativa que o sábado. A oportunidade dos trabalhadores de fim de semana para reprogramar o tempo de lazer compartilhado é limitada uma vez que os outros estão menos disponíveis durante a semana. Apenas os trabalhadores de fim de semana que trabalhavam a tempo parcial, recuperavam algum tempo de lazer durante a semana seguinte (principalmente com amigos).

Por sua vez, o estudo de Shen e Dicker (2008) analisou o impacto do trabalho por turnos diretamente junto dos trabalhadores por turnos, tendo verificado que estes, de modo geral, reportaram dificuldade em manter um relacionamento conjugal saudável e que, em termos de vida social, esta era sobretudo afetada quando o horário de trabalho ocorria aos fins de semana, dificultando as relações de amizade (o contacto com os amigos). No estudo de Silva et al. (2014), onde o impacto do trabalho por turnos foi avaliado junto dos próprios trabalhadores, foram analisados os comentários destes acerca do impacto de tal modalidade horária em relação a dimensões de saúde e da vida familiar e social, tendo a proporção dos comentários - positivos e negativos - variado consoante o turno em questão. Especificamente, o horário de turno da manhã e da tarde apresentam mais aspetos positivos do que negativos, ao passo que os turnos que solicitam trabalho noturno (tanto em regime permanente como rotativo) exibiram, aspetos mais negativos.

Para além da perspetiva do próprio trabalhador, os cônjuges podem ser uma fonte de grande valor no que diz respeito à compreensão do impacto do trabalho por turnos nas esferas familiar e social. Estes serão as pessoas mais próximas dos trabalhadores por turnos, encontrando-se, por conseguinte, numa situação privilegiada para compreender os problemas enfrentados pelo trabalhador por turnos, além de poderem mesmo influenciar a experiência de trabalhar em turnos pelo suporte que podem dar ao trabalhador sujeito a esse regime horário (Newey \& Hood, 2004). Smith e Folkard (1993b), no seu estudo sobre o impacto do trabalho por turnos na perspetiva das esposas/companheiras dos trabalhadores por turnos (todos os trabalhadores por turnos eram do sexo masculino e os respetivos cônjuges todos do sexo feminino), indicaram a existência de um elevado nível de insatisfação. Com efeito, mais de metade das companheiras relataram estar descontentes, ou muito descontentes pelo facto dos seus companheiros trabalharem por turnos. Este nível de descontentamento foi transmitido nas apreciações da "conflitualidade com o cônjuge", "necessidade de adaptar a organização da vida familiar e social ao sistema de turnos" e "empobrecimento da vida social realizada em conjunto". As companheiras associaram ainda o turno noturno a maiores problemas para o trabalhador a nível da fadiga/sono, saúde, familiares e sociais bem como a "mudanças de humor e personalidade". 0 estudo de Costa e Silva (2019), alicerçando-se também no instrumento utilizado no estudo anteriormente mencionado, analisou a interferência do trabalho por turnos na vida familiar e social com base numa amostra constituída por 515 cônjuges/companheiros(as) de polícias portugueses, sendo que 403 eram cônjuges/companheiros(as) de trabalhadores por turnos e 112 de trabalhadores diurnos. Os resultados obtidos indicaram um impacto moderado a elevado do trabalho por turnos em todos os itens do questionário, com especial interferência nas dimensões "reorganização/planeamento constante da vida pessoal e familiar" e "vida social pessoal ou conjunta”. 
Quanto à comparação do impacto do trabalho por turnos na vida familiar e social integrando ambas as perspetivas - "trabalhador(a) e seu cônjuge" - a investigação é bastante escassa e apenas realizada em contexto internacional como é o caso do estudo de Handy (2010) e o de Newey \& Hood (2004). De modo específico, o estudo de Newey \& Hood (2004) avaliou o nível de congruência entre trabalhador(a) por turnos e os(as) seus/suas parceiros(as) em relação ao impacto do trabalho por turnos a nível do sono/fadiga, saúde, stress e vida social e familiar. Foram aplicadas duas versões do questionário de Smith e Folkard (1993a, b) para avaliar as perceções dos dois membros do casal no que diz respeito às áreas mencionadas anteriormente tendo em conta os diferentes horários (dia, tarde e noite). A amostra foi constituída por 59 profissionais de enfermagem (dos quais, 54 trabalhavam por turnos rotativos) e seus/suas parceiros(as) (24 deles(as) também trabalhadores(as) por turnos) na Austrália. Os resultados indicaram que as perceções dos/as trabalhadores/as por turnos e dos seus/suas parceiros(as) eram congruentes face ao impacto percecionado do trabalho por turnos na "vida familiar" e na "vida social", tendo estas duas esferas da vida sido avaliadas pelos membros do casal como as mais afetadas pelo trabalho por turnos quando comparadas com as restantes (sono/fadiga, saúde e stress), congruência essa que segundo os autores, poderia advir do facto de muitos dos(as) parceiros(as) serem também eles(as) próprios(as) trabalhadores(as) por turnos. Por outro lado, ambos os membros consideraram que tais esferas da vida eram menos afetadas quando o turno era realizado durante o dia e eram mais afetadas em conexão com o turno da noite.

No estudo de Handy (2010), por sua vez, foram entrevistados 27 trabalhadores por turnos e 17 das respetivas parceiras, incluindo 12 casais, tendo sido analisado o impacto do trabalho por turnos a longo prazo nas famílias dos trabalhadores de uma empresa petroquímica da Nova Zelândia. 0 estudo concluiu que as rotinas familiares e a vida social tinham de se adaptar ao horário do trabalhador por turnos. Embora esse impacto fosse sentido nas duas perspetivas, a sua concentração variava. Assim, enquanto as preocupações dos trabalhadores por turnos se concentravam na dificuldade em adaptar-se às rotinas familiares depois de um turno noturno, as parceiras concentravam-se nas estratégias para coordenar as rotinas familiares de modo a garantir a acomodação aos horários dos trabalhadores.

\section{Objetivos}

Partindo da revisão de literatura descrita e da falta de estudos que analisem o impacto do trabalho por turnos na vida familiar e social tendo em conta a perspetiva do/a trabalhador/a e do seu cônjuge, o presente estudo tem como principal objetivo analisar o impacto do trabalho por turnos na vida familiar e social no casal, tendo em conta a perspetiva do(a) próprio(a) trabalhador(a) e a do(a) seu/sua cônjuge/companheiro(a). Especificamente pretende-se: i) analisar se existem diferenças do impacto do trabalho por turnos rotativos na vida familiar e social entre os dois membros da díade trabalhador(a) cônjuge e ii) analisar o impacto do trabalho por turnos na díade comparando diferentes horários de trabalho (Rotativo - Rotativo; Rotativo - Normal).

\section{MÉTODO}

\section{Participantes}

A amostra é composta por 51 casais, onde pelo menos um dos membros trabalha por turnos rotativos (grupo dos(as) trabalhadores(as)) e o outro membro é o(a) seu/sua respetivo(a) cônjuge/companheiro(a) (por questões de facilidade passaremos a designar este grupo ao longo do texto como grupo dos cônjuges).

No que diz respeito ao grupo dos(as) trabalhadores(as), com 51 participantes, em média, estes têm idades compreendidas entre os 24 e os 57 anos $(M=38.51, D P=8.02)$, dos quais $52.9 \%$ são do sexo masculino. Quanto aos níveis de escolaridade, o 3.ำ ciclo do ensino básico e o ensino secundário são os mais representativos, ambos com 37.3\%. Em média, os(as) trabalhadores(as) encontram-se na profissão atual há 14.20 anos $(D P=8.96)$ e laboram no mesmo horário de trabalho há 13.48 anos $(D P=8.23)$.

Por sua vez, no grupo dos cônjuges, as idades estão compreendidas entre os 21 e os 63 anos $(M=$ $38.76, D P=8.83$ ), dos quais $47.1 \%$ são do sexo masculino. No que diz respeito ao nível de escolaridade, $41.2 \%$ da amostra deste grupo tem o ensino secundário. Quanto ao horário de trabalho praticado pelos cônjuges, um terço tem o horário normal e outro um terço tem um horário de trabalho por turnos rotativos. A média de anos de união é 12.84 ( $D P=7.87)$. Uma análise mais detalhada dos elementos caracterizadores de cada grupo encontra-se na Tabela 1.

A maioria dos agregados familiares é composto por 4 pessoas. $70.6 \%$ dos casais têm filhos. Destes, a maioria tem um filho sendo a classe "7 aos 12 anos" a mais prevalente (29.6\%). Em termos de distribuição geográfica (concelhos), os dados estavam distribuídos da seguinte forma: Braga (72.6 \%), Barcelos (3.9\%), Famalicão (3.9\%), Fafe (2.0\%), Terras de Bouro (2.0\%) e Amares (1.0\%). 
Tabela 1. Caracterização sociodemográfica e profissional dos trabalhadores(as) por turnos e seus cônjuges

\begin{tabular}{|c|c|c|c|c|}
\hline \multirow{2}{*}{ Variáveis } & \multicolumn{2}{|c|}{ Trabalhador(a) } & \multicolumn{2}{|c|}{ Cônjuge } \\
\hline & $\mathbf{n}$ & $\%$ & $\mathbf{n}$ & $\%$ \\
\hline \multicolumn{5}{|l|}{ Sexo } \\
\hline Masculino & 27 & 52.9 & 24 & 47.1 \\
\hline Feminino & 24 & 47.1 & 27 & 52.9 \\
\hline \multicolumn{5}{|l|}{ Idade } \\
\hline Média (desvio-padrão) & \multicolumn{2}{|c|}{$38.51(8.02)$} & \multicolumn{2}{|c|}{$38.76(8.83)$} \\
\hline \multicolumn{5}{|l|}{ Nível de escolaridade } \\
\hline 1ํ Ciclo do Ensino Básico & 1 & 2.0 & 0 & 0.0 \\
\hline 2 Ciclo do Ensino Básico & 1 & 2.0 & 4 & 7.8 \\
\hline 3ํㅡㄹ Ciclo do Ensino Básico & 19 & 37.3 & 16 & 31.4 \\
\hline Ensino Secundário & 19 & 37.3 & 21 & 41.2 \\
\hline Ensino Superior & 7 & 13.7 & 8 & 15.7 \\
\hline Outro & 2 & 3.9 & 1 & 2.0 \\
\hline \multicolumn{5}{|l|}{ Horário de trabalho } \\
\hline Horário normal & -- & -- & 17 & 33.3 \\
\hline Horário da manhã & -- & -- & 3 & 5.9 \\
\hline Horário da tarde & -- & -- & 1 & 2.0 \\
\hline Horário da noite & -- & -- & 1 & 2.0 \\
\hline Trabalho por turnos rotativos & 51 & 100.0 & 17 & 33.3 \\
\hline Outro & -- & -- & 5 & 9.8 \\
\hline \multicolumn{5}{|l|}{ Anos na profissão atual } \\
\hline Média (desvio-padrão) & \multicolumn{2}{|c|}{$14.20(8.96)$} & \multicolumn{2}{|c|}{--} \\
\hline \multicolumn{5}{|c|}{ Anos a trabalhar em turnos rotativos } \\
\hline Média (desvio-padrão) & \multicolumn{2}{|c|}{$13.48(8.23)$} & \multicolumn{2}{|c|}{--} \\
\hline \multicolumn{5}{|l|}{ Situação profissional do cônjuge } \\
\hline Trabalha a tempo inteiro & -- & -- & 42 & 82.4 \\
\hline Trabalha a tempo parcial & -- & -- & 2 & 3.9 \\
\hline Desempregado/a & -- & -- & 4 & 7.8 \\
\hline Trabalho doméstico & -- & -- & 1 & 2.0 \\
\hline Reformado & -- & -- & 1 & 2.0 \\
\hline \multicolumn{5}{|l|}{ Cônjuge já trabalhou por turnos? } \\
\hline $\operatorname{Sim}$ & -- & -- & 20 & 39.2 \\
\hline Não & -- & -- & 25 & 49.0 \\
\hline
\end{tabular}

Nota. Cada grupo (trabalhadores e cônjuges) era constituído por 51 participantes, contudo em algumas variáveis o n pode ser diferente devido à presença de valores omissos nessas mesmas variáveis. De salientar que, todos os trabalhadores avaliados laboravam em trabalho por turnos rotativos. A antiguidade na profissão e no horário de trabalho apenas foram calculadas para o grupo dos trabalhadores. Ao invés das duas últimas variáveis apresentadas na Tabela que apenas foram respondidas pelo grupo dos(as) cônjuges.

Sistema de Rotação. Os(as) trabalhadores(as) por turnos rotativos que compõem esta amostra encontram-se divididos por quatro equipas de trabalho, sendo que todas elas trabalham segundo o mesmo sistema rotativo. Este horário é estruturado em três turnos de oito horas cada, sete/seis dias por semana. Ou seja, sete dias a trabalhar das 8:00-16:00, com dois dias de folga subsequentes; sete dias a trabalhar das 16:00-24:00, com dois dias de folga subsequentes e seis dias a trabalhar das 24:00-8:00 com quatro dias de folga subsequentes. Considerando uma das escalas elaboradas, um exemplo seria: enquanto a equipa A realiza o turno das 8:00-16:00 durante sete dias, a equipa $B$, nesse mesmo tempo, folga os dois primeiros dias e nos restantes começa o horário das 16:00-24:00, por sua vez a equipa $C$, trabalha dois dias das 16:00-24:00, folga dois dias e inicia nos restantes três dias o turno das 24:00-8:00, 
por fim a equipa D encontra-se nos últimos três dias no turno das 24:00-8:00 e segue com quatro dias de folga.

\section{Instrumentos}

Na recolha de dados foram utilizados dois protocolos de avaliação constituídos por duas partes: a primeira correspondia ao questionário sociodemográfico e profissional, enquanto a segunda englobava o questionário para avaliar os impactos do trabalho por turnos na vida familiar e social.

Enquanto a primeira parte dos protocolos de avaliação era igual e tinha como finalidade recolher informação sociodemográfica dos participantes (e.g., estado civil), assim como dados sobre a sua situação familiar (e.g., número de filhos) e profissional (e.g., horário de trabalho), a segunda parte diferenciava-se entre os grupos de participantes, pois a cada um correspondia uma versão do Questionário sobre o impacto do trabalho por turnos - "versão trabalhador" ou "versão cônjuge".

O Questionário sobre o impacto do trabalho por turnos na perspetiva dos familiares (Costa, 2016; Costa \& Silva, 2019) corresponde à tradução e adaptação para o contexto português do "Shiftworker partners questionnaire" de Smith e Folkard (1993b). Este questionário tinha como objetivo avaliar o impacto do trabalho por turnos na esfera familiar e social dos trabalhadores por turnos, segundo a perspetiva dos(as) seus/suas cônjuges/companheiros(as).

A versão portuguesa era constituída por 15 itens, avaliados numa escala tipo Likert de 0 a 10 pontos, significando os valores mais altos, maior disrupção. Da análise das características psicométricas da escala utilizada, realizada por Costa e Silva (2019), emergiram dois fatores: um primeiro fator que englobava itens mais relacionados com o planeamento e a reorganização da vida familiar e social (e.g., " $O$ trabalho por turnos (a) seu(sua) cônjuge/companheiro(a) interfere com a vida social conjunta? (ou seja, se o trabalho por turnos do(a) seu(sua) cônjuge/companheiro(a) impediu as saídas em conjunto, tanto quanto você gostaria?)"), por questões de facilidade, passaremos a designá-lo ao longo do texto por "Vida Familiar e Social", enquanto o segundo fator englobava itens mais focados no relacionamento entre o(a) trabalhador(a) por turnos e os seus familiares, principalmente cônjuges (e.g., "Alguma vez já teve alguma desavença ou conflito com o(a) seu(sua) cônjuge/companheiro(a) que sinta que foi devido ao seu horário de trabalho por turnos?") e à semelhança do anterior, passaremos a designá-lo por "Vida do Casal". 0 fator "Vida Familiar e Social" era constituído por nove itens e apresentava um alfa de Cronbach de 0.95, enquanto o fator "Vida do Casal", constituído por seis itens, revelou um alfa de Cronbach de 0.84. Além desta escala, o questionário continha ainda nove questões complementares, algumas das quais incluímos no presente estudo, nomeadamente três perguntas referentes ao contacto entre o(a) trabalhador(a) por turnos e os(as) seus/suas filhos(as), em três momentos diferentes do dia (manhã, tarde e noite), também avaliadas numa escala tipo Likert de 0-10 pontos, e duas perguntas abertas: uma referente à perceção que o grupo dos(as) cônjuges tinha do impacto que o trabalho por turnos dos(as) seus/suas cônjuges (neste caso, o grupo dos(as) trabalhadores(as) por turnos) provocava nas crianças e outra sugestões/comentários acerca do tema abordado. A partir desta "versão cônjuge", foi construída uma versão para o próprio trabalhador por isomorfismo, tendo tal versão sido submetida a uma aplicação préteste (descrita no ponto seguinte).

\section{Procedimento}

Após o projeto de investigação ter sido submetido à Comissão de Ética da Universidade do Minho e ter obtido parecer favorável (Referência SECSH 043/2017), foi estabelecido contacto com uma organização do setor industrial, a qual se mostrou interessada no estudo. Previamente, foi realizada uma reunião com a responsável de Recursos Humanos e o responsável do setor do trabalho por turnos da organização, para clarificação do propósito do estudo. Uma vez autorizada a recolha de dados pela organização, foi efetuada uma reunião para efeitos de aplicação do pré-teste de ambas as versões do questionário, onde estiveram presentes três trabalhadores do setor de turnos para explicitação do procedimento e solicitação de entrega aos respetivos cônjuges. Tanto a "versão trabalhador" como a "versão cônjuge" foram preenchidas em casa, por questões de tempo de produção, tendo neste contexto sido reforçada junto dos trabalhadores a importância de os questionários serem preenchidos individualmente. Desta aplicação pré-teste foram introduzidas algumas melhorias no questionário, sobretudo o nível do seu layout.

Na impossibilidade da recolha de dados ser realizada pelos investigadores, esta foi conduzida pelo responsável do setor onde estava implementado o regime de trabalho por turnos. Assim, foi necessário efetuar reuniões onde o procedimento de recolha foi explicado, de forma clara, deixando um documento escrito com todos os passos a serem seguidos. A recolha de dados foi dividida em dois momentos, sendo a primeira recolha aplicada em duas equipas e a segunda nas duas restantes. Foram considerados como critérios de inclusão: i) estar num relacionamento conjugal; ii) trabalhador(a) e cônjuge coabitarem juntos e iii) trabalhador(a) estar a exercer a sua função em trabalho por turnos rotativos há pelo menos 
um mês. Ambos os questionários estavam identificados por um código alfanumérico, que meramente ajudava a identificar as duas pessoas como casal, para a realização da análise "trabalhadores e seus cônjuges". Em momento algum este método quebrou as regras de confidencialidade e anonimato.

A recolha de dados ocorreu entre o final de fevereiro e início de abril de 2018, tendo implicado sempre uma reunião de aplicação da recolha de dados com o responsável do setor antes das mesmas sucederem, para explicitação de todas as fases do processo. Pretendeu-se que a amostra fosse o mais representativa possível, aplicando-se 160 questionários na primeira recolha e 160 na segunda. No entanto, apenas foram devolvidos 102 e 21 respetivamente. Dos primeiros 102 questionários não foram utilizados 18, por casos de troca de questionários (trabalhador(a) preencheu o do cônjuge e vice-versa), não preenchimento de ambos os questionários ou preenchimento apenas de um questionário. Dos 21, não foram utilizados seis, devido a troca do questionário como nos casos anteriores.

Procedimento de análise de dados. $\mathrm{Na}$ análise dos dados quantitativos foi utilizado o programa Statistical Package for the Social Sciences (IBM® SPSS®, versão 24) para realização de análises descritivas (médias, desvios-padrão), análises inferenciais para associação entre variáveis (coeficiente de correlação de Spearman) e para comparação de grupos (teste $t$ de Student) seguindo as recomendações de Field (2013). Por sua vez, os dados qualitativos resultantes das duas questões abertas foram analisados com o método de análise de conteúdo (Bardin, 2009).

\section{RESULTADOS}

Nesta secção serão apresentados os resultados da análise de diferenças da perceção do impacto do trabalho por turnos rotativos na vida conjugal e social entre os dois membros da díade trabalhador(a) cônjuge, ou seja, em que medida a avaliação do impacto do trabalho por um dos membros da díade é influenciada pela avaliação feita pelo outro membro da díade; serão ainda apresentados resultados da análise do impacto do trabalho por turnos na díade, tendo em conta os diferentes horários de trabalho de cada membro do casal, assim como uma análise de conteúdo da resposta dos(as) trabalhadores(as) e dos seus cônjuges à questão opcional.

A análise de dados teve por base a análise fatorial de Costa e Silva (2019), onde as autoras dividem as dimensões do questionário que aplicamos nesta análise em duas dimensões: i) uma dimensão referente ao impacto do trabalho por turnos na vida de casal e ii) uma dimensão relativa à vida familiar e social, como podemos ver na Tabela 2. No entanto, nesta análise introduzimos também as questões adicionais avaliadas numa escala tipo Likert de 0-10 pontos, alusivas aos/às filhos(as) (i.e., contacto parental do trabalhador durante os três turnos: manhã, tarde e noite) como anteriormente mencionado na descrição do questionário.

Tabela 2. Subescala e agrupamento dos itens do "Questionário sobre o impacto do trabalho por turnos na perspetiva dos familiares"

\begin{tabular}{lc}
\hline Itens & Subescala \\
\hline 6. Vida social conjunta & \\
7. Reorganização familiar/conjugal & \\
8.1. Cônjuge alterar nível de Ruído & \\
8.2. Cônjuge alterar horários de refeições & Fator “Vida Familiar e Social” \\
8.3. Cônjuge ter maior responsabilidade parental & Alfa de Cronbach =0.95 \\
8.4. Cônjuge sozinho durante o dia & \\
8.5. Cônjuge sozinho durante a tarde & \\
8.6. Cônjuge sozinho durante a noite & \\
9. Vida familiar ou pessoal do cônjuge & \\
\hline
\end{tabular}

\footnotetext{
1. Sentimentos do cônjuge acerca do trabalho por turnos

3. Conflito conjugal

4. Relação conjugal prejudicada

5. Relação íntima prejudicada

Fator "Vida de Casal"

Alfa de Cronbach $=0.84$

12. Contacto do trabalhador com as crianças

10. Trabalhador troca de turno facilmente

Nota. Adaptado de "Social and family life impact of shift work from the perspective of family members" de D. Costa e I. Silva, 2019, Revista de Administração de Empresas, 59(2), 108-120.
} 
Análise de diferenças do impacto do trabalho por turnos rotativos na vida familiar e social entre os dois membros da díade trabalhador(a) - cônjuge

Começamos por analisar o comportamento dos itens individuais na amostra geral, nomeadamente quanto ao grau de acordo e quanto ao grau de perturbação na díade atribuída ao trabalho por turnos (Figura 1), tendo nessa análise seguido as recomendações de Kenny et al. (2006).

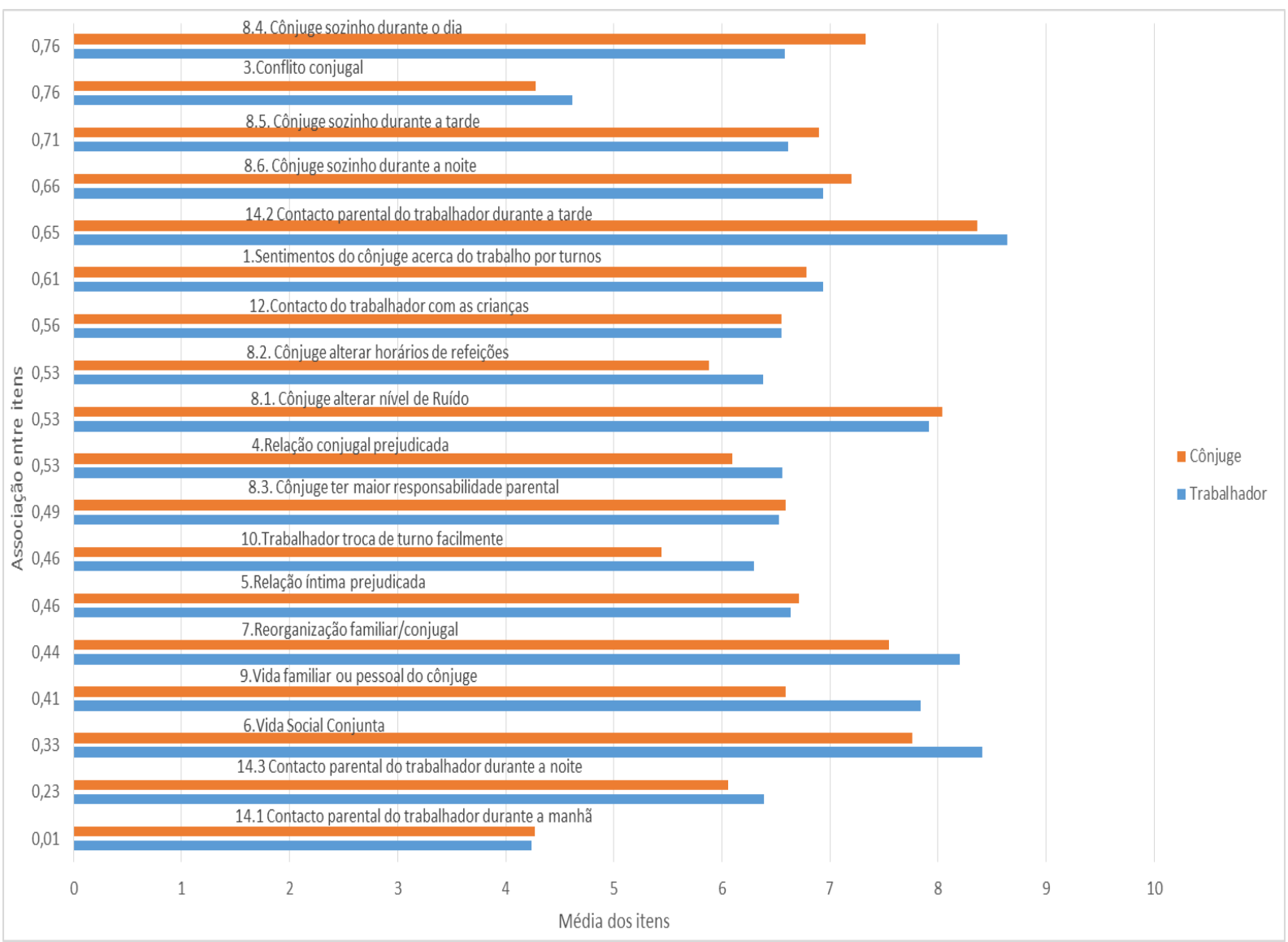

Figura 1. Médias das estimações do impacto do trabalho por turnos e associações entre trabalhador/a e cônjuge.

Embora as correlações sejam todas significativas ( $p$ (spearman) $<0.05, n=51$ pares) (eixo das ordenadas do gráfico), estas correlações variam de item para item, o que pode sugerir variação quanto à coordenação dentro da díade. A ausência de outras diferenças estatisticamente significativas entre as respostas de trabalhadores(as) e cônjuges, a par com as correlações significativas, pode sugerir também que as avaliações se estabelecem de formas semelhantes na díade, em relação à grande maioria das questões levantadas pelo questionário. A exploração das variações item a item no interior das díades, além de excessivamente fragmentada, julgámos que não traria muito mais informação para compreendermos o impacto do trabalho por turnos nas díades. Assim sendo, na restante análise destes dados, optámos por usar as variáveis agregadas nas duas subescalas do questionário no sentido de explorar as diferenças entre agrupamentos de díades.

\section{Análise de diferenças entre agrupamentos de díades}

Com base na análise fatorial descrita na Tabela 2, foram calculadas quatro variáveis diferentes: a) "vida familiar e social" do ponto de vista do/a trabalhador/a; b) "vida familiar e social" do ponto de vista do cônjuge; c) "vida de casal" do ponto de vista do/a trabalhador/a e d) "vida de casal" do ponto de vista do cônjuge.

A análise de acordo dentro das díades quanto a estas variáveis (ver Tabela 3) mostra uma associação moderada entre os dois conjuntos de itens, com médias semelhantes, o que sugere um acordo moderado dentro das díades. Provavelmente tal resulta da inclusão, na nossa amostra, de situações muito diversas perante o trabalho, pelo que procuramos estudar o efeito de uma dessas condições (neste caso, o tipo de horário de trabalho) sobre as avaliações das díades. 
Tabela 3. Grau de acordo nas variáveis agregadas

\begin{tabular}{lcccccc}
\hline & $\begin{array}{c}\text { Correlação } \\
\text { Spearman } \\
\text { entre } \\
\text { membros do } \\
\text { casal }\end{array}$ & $\begin{array}{c}\boldsymbol{P} \\
\text { (Spearman) }\end{array}$ & $\begin{array}{c}\text { Trabalhador } \\
\text { M (DP) }\end{array}$ & $\begin{array}{c}\text { Cônjuge } \\
\text { M (DP) }\end{array}$ & $\boldsymbol{t}$ (g.l.) & $\boldsymbol{p}$ \\
\hline Vida de casal & 0.54 & 0.00 & $6.22(2.01)$ & $6.02(1.98)$ & $0.52(98)$ & 0.60 \\
Vida familiar e social & 0.65 & 0.00 & $7.29(2.20)$ & $7.12(2.55)$ & $0.36(98)$ & 0.72 \\
\hline
\end{tabular}

Nota. M = média; DP = desvio-padrão; g.l. = graus de liberdade obtidos no test $t$ de Student.

\section{Análise do impacto do trabalho por turnos na díade tendo em conta os diferentes horários de trabalho de cada membro do casal}

Um dos agrupamentos realizáveis desta análise, dado tratar-se da compreensão dos efeitos do trabalho por turnos rotativos, é a divisão das díades entre aquelas em que ambos os membros trabalham por turnos rotativos e as díades em que apenas um dos membros trabalha dessa forma. Relembramos que no modo como a recolha dos dados foi definida (critérios de inclusão), existe sempre um membro da díade que trabalha por turnos rotativos, no entanto a situação dos cônjuges pode variar (cf., descrição da Tabela 1, "Horário de trabalho" do cônjuge).

Descrição dos agrupamentos de díade. Os dois grupos de díades (rotativo-rotativo e rotativo-normal), representados na Tabela 4, correspondem a cerca de dois terços da nossa amostra. 0 restante terço inclui situações muito diferentes perante o trabalho no que respeita ao cônjuge (desempregado, reformado, faz outros tipos de horários, etc.), pelo que optámos por excluir este grupo desta comparação.

Tabela 4. Indicadores de acordo para as variáveis agregadas

\begin{tabular}{|c|c|c|c|c|c|c|}
\hline & \multicolumn{3}{|c|}{ Rotativo - Rotativo } & \multicolumn{3}{|c|}{ Rotativo - Normal } \\
\hline & $N$ & M (DP) & $\begin{array}{c}p \\
\text { (Spearman) } \\
\end{array}$ & $N$ & M (DP) & $\begin{array}{c}p \\
\text { (Spearman) } \\
\end{array}$ \\
\hline $\begin{array}{l}\text { Vida familiar e social } \\
\text { (Perspetiva trabalhador) }\end{array}$ & 17 & $7.22(2.44)$ & \multirow[b]{2}{*}{$0.64^{* *}$} & 16 & $7.36(1.89)$ & \multirow[b]{2}{*}{$0.633^{* *}$} \\
\hline $\begin{array}{l}\text { Vida familiar e social } \\
\text { (Perspetiva cônjuge) }\end{array}$ & 17 & $6.48(3.16)$ & & 17 & $7.79(1.63)$ & \\
\hline $\begin{array}{l}\text { Vida de casal } \\
\text { (Perspetiva trabalhador) }\end{array}$ & 17 & $6.91(2.01)$ & \multirow{2}{*}{0.172} & 16 & $6.10(1.48)$ & \multirow{2}{*}{$0.759^{* *}$} \\
\hline $\begin{array}{l}\text { Vida de casal } \\
\text { (Perspetiva cônjuge) }\end{array}$ & 17 & $6.14(1.71)$ & & 17 & $5.81(1.92)$ & \\
\hline
\end{tabular}

Nota. $\mathrm{M}=$ média; DP = desvio-padrão; ${ }^{*} p<.05 ;{ }^{* *} p<.01 ;{ }^{* * *} p<.001$

No que respeita às médias das variáveis nos dois grupos, há apenas uma diferença marginalmente significativa entre os dois grupos na variável "Vida de Casal", do ponto de vista do trabalhador $\left(t_{(\text {Welch })}=\right.$ 1.32 , g.l. $=31.17 ; p=0.10)$, com os trabalhadores das díades rotativo-rotativo avaliando mais negativamente o impacto deste horário.

Já no que respeita às correlações, um teste de igualdade de correlações (dado as correlações serem não paramétricas seguimos a sugestão de Myers e Sirois (2014), de tratar estas comparações como se ambas as correlações fossem paramétricas) mostrou que existe uma diferença significativa, entre os dois grupos de díades, das correlações entre o ponto de vista do cônjuge e o ponto de vista do trabalhador sobre dimensões da vida conjugal $(z=-2.129 ; p=0.02)$ : no grupo rotativo-rotativo esta correlação é significativamente mais baixa do que no grupo rotativo-normal.

\section{Perceção dos impactos do trabalho por turnos nas dimensões avaliadas}

0 gráfico apresentado anteriormente na Figura 1, permite também analisar o grau de perturbação provocado pelo horário de trabalho por turnos rotativo na perceção do trabalhador e do cônjuge (eixo das abcissas) nos itens/questões avaliados (relembramos que esta avaliação foi feita numa escala de 10 pontos sendo que quanto maior o valor, maior a perceção de interferência do trabalho por turnos).

De um modo geral, pode dizer-se que o impacto do trabalho por turnos na maioria dos itens varia entre moderado a elevado. De modo mais específico, os dois itens melhor avaliados quer na perspetiva dos trabalhadores(as) quer na do cônjuges correspondem ao item 14.1. "Contacto parental entre trabalhador e o(s) filho(s) durante a manhã.", tendo os valores médios obtidos sido de $4.24(D P=2.97) \mathrm{e}$ $4.12(D P=2.77)$ e ao item 3. "Conflito conjugal": perspetiva do trabalhador(a) $(M=4.62, D P=3.02)$ e 
perspetiva do cônjuge $(M=4.28, D P=2.95)$. Em contrapartida, os itens avaliados como existindo uma perceção de maior interferência do trabalho por turnos em ambas as perspetivas foram os seguintes: item 14.2. "Contacto parental entre o trabalhador e o(s) filho(s) durante a tarde." (trabalhador(a): $M=8.64, D P=$ 2.19 e cônjuge: $M=8.36, D P=2.10$ ) e item 6. "Vida social conjunta" (trabalhador(a): $M=8.41, D P=2.52$ e cônjuge: $M=7.76, D P=3.06)$.

\section{Análise de conteúdo das respostas dos(as) trabalhadores(as) e dos seus cônjuges às questões abertas}

Como referido anteriormente, a análise das respostas dos participantes às questões abertas foi feita utilizando o método de análise de conteúdo (Bardin, 2009). Primeiramente, foi realizada uma leitura aprofundada, sendo de seguida explorado o conteúdo das respostas por duas pessoas de forma independente, tendo por base a literatura. Posteriormente, a análise foi realizada conjuntamente, de modo a discutir possíveis desacordos na criação do sistema de categorização. Num segundo momento, os resultados desta análise foram discutidos no grupo de investigação a que a equipa de autores pertence, no intuito de afinar o sistema de categorização elaborado.

Relativamente à questão aberta que abordou o impacto do trabalho por turnos rotativos no contacto entre o trabalhador(a) e a(s) criança(s), foram obtidas 25 (56.8\%) respostas dos trabalhadores(as) e 19 (43.2\%) respostas dos cônjuges. Foi possível identificar quatro categorias alusivas à perspetiva dos(as) trabalhador(as) e três à perspetiva dos cônjuges. Como podemos verificar na Tabela 5, duas dessas categorias mostraram-se mais frequentes em cada grupo. Tanto os(as) trabalhadores(as) como os seus cônjuges reportaram com maior frequência as categorias "Acompanhar desenvolvimento das crianças" e "Disponibilidade para comunicação/interação familiar" como sendo as mais afetadas pelo trabalho por turnos rotativos. Dentro da primeira categoria, podemos identificar o impacto negativo no acompanhamento dos trabalhadores na vida e crescimento do(s) seu(s) filho(s) com maior expressão nas subcategorias, "Escolar" e "Atividades de lazer" nos dois grupos. Alguns exemplos dados pelos trabalhadores nestas subcategorias foram "Não poder estar disponível quando acontece algo na escola, por exemplo, reuniões escolares, feiras."; "Acompanhamento escolar e tempo livre de lazer.". Um dos exemplos dados pelos cônjuges englobando as duas subcategorias foi "Indisponibilidade para atuar nas atividades escolar e outras (sociais, desportivas, pessoais, etc.).". Dentro da segunda categoria mais afetada pelo trabalho por turnos rotativos, as subcategorias "Turno da tarde" e "Interação nos fins-de-semana" foram as mais destacadas nos dois grupos, indicativa do pouco tempo que o(a) trabalhador(a) tinha disponível para interação com a(s) criança(s) durante o dia/semana. Um dos trabalhadores referiu "Principalmente ao fim-de-semana quando estamos a trabalhar e no turno das 16 às 24, praticamente só nos vemos de manhã!". Alguns dos exemplos mencionados pelos cônjuges foram "A semana que faz das 16 às 24 horas, praticamente não fala com os filhos. Quando chega, os filhos já dormem e de manhã ou se levanta cedo para estar com eles antes de saírem para a escola ou então não fala com os filhos a semana toda.", "Os meus filhos deveriam passar mais tempo com o pai, não conseguimos ter um fim de semana completo por causa dos turnos.".

No que diz respeito à segunda questão aberta - "comentários sobre o impacto do horário de trabalho do(a) trabalhador(a)" (Tabela 6) foram obtidas 12 (54.5\%) respostas por parte dos(as) trabalhadores(as) e 10 (45.5\%) por parte dos(as) seus cônjuges. No que concerne aos comentários, as categorias destacadas como mais afetadas pelo horário rotativo foram "Impacto a nível da saúde" e "Impacto a nível familiar/conjugal". Na primeira categoria foi dado destaque pelos(as) trabalhadores(as) à interferência no ritmo de sono, a nível físico e na saúde e bem-estar, já na segunda o impacto foi mencionado como tendo interferência no tempo dedicado à família. - "A rotatividade de horário afeta não só a vida familiar, (...) essencialmente a reposição das horas de sono; com as consequências que isto acarreta para a saúde e o bem-estar". No que diz respeito aos cônjuges, as categorias mais afetadas por esta modalidade horária foram similares às dos(as) trabalhadores(as), embora com menos frequência. Na primeira categoria foi dado maior destaque ao nível psicológico, já na segunda categoria o impacto foi mencionado a nível conjugal, tempo com os filhos e o esforço de ajustamento dos filhos aos horários dos progenitores que laboram por turnos rotativos. 
Tabela 5. Categorias obtidas à questão alusiva ao contacto insuficiente entre o trabalhador(a) criança(s), considerando as perspetivas dos(as) trabalhadores(as) e dos cônjuges

\begin{tabular}{|c|c|c|c|}
\hline \multicolumn{2}{|c|}{ Trabalhador } & \multicolumn{2}{|r|}{ Cônjuge } \\
\hline Categorias & Subcategorias & Categorias & Subcategorias \\
\hline \multirow{7}{*}{$\begin{array}{l}\text { Acompanhar } \\
\text { desenvolvimento } \\
\text { das crianças }(19)^{*}\end{array}$} & Escolar (9) & \multirow{7}{*}{$\begin{array}{l}\text { Acompanhar } \\
\text { desenvolvimento } \\
\text { das crianças }(14)^{*}\end{array}$} & \\
\hline & Atividades de lazer (3) & & Escolar (6) \\
\hline & Atividades Lúdicas (2) & & Atividades de lazer (5) \\
\hline & Saúde (2) & & Crescimento (2) \\
\hline & Físico (1) & & Saúde (1) \\
\hline & Intelectual (1) & & \\
\hline & Educação parental (1) & & \\
\hline \multirow{5}{*}{$\begin{array}{l}\text { Disponibilidade } \\
\text { para comunicação / } \\
\text { interação familiar } \\
(16)^{*}\end{array}$} & Turno da tarde (8) & \multirow{5}{*}{$\begin{array}{l}\text { Disponibilidade } \\
\text { para comunicação / } \\
\text { interação familiar } \\
(12)^{*}\end{array}$} & Interação aos fins-de-semana (4) \\
\hline & $\begin{array}{l}\text { Interação nos fins-de-semana } \\
\text { (3) }\end{array}$ & & Turno da tarde (3) \\
\hline & $\begin{array}{l}\text { Disponibilidade em momentos } \\
\text { importantes (2) }\end{array}$ & & Partilha de ideias/emoções (2) \\
\hline & $\begin{array}{l}\text { Comunicação pais - criança(s) } \\
\text { (2) }\end{array}$ & & Refeições (2) \\
\hline & Refeições (1) & & Comunicação em família (1) \\
\hline \multirow{2}{*}{$\begin{array}{l}\text { Procura do Suporte } \\
(3)^{*}\end{array}$} & Avós (2) & \multirow{2}{*}{---} & \multirow{2}{*}{---} \\
\hline & Tios (1) & & \\
\hline \multirow{4}{*}{ Vínculo afetivo (2)* } & \multirow{4}{*}{ Saudades do progenitor (2) } & \multirow{4}{*}{ Vínculo afetivo (5)* } & Saudades do progenitor (2) \\
\hline & & & $\begin{array}{l}\text { Criança não percebe o porquê de } \\
\text { não estarem todos juntos (1) }\end{array}$ \\
\hline & & & Emocional (1) \\
\hline & & & Da criança com o trabalhador (1) \\
\hline
\end{tabular}

Nota. *0 total das frequências pode ser superior ao número de respostas obtidas, dado que determinadas respostas podem conter mais de uma categoria.

Tabela 6. Comentários sobre o horário de trabalho dos(as) trabalhadores(as) por turnos

\begin{tabular}{|c|c|c|c|}
\hline \multicolumn{2}{|c|}{ Trabalhador } & \multicolumn{2}{|r|}{ Cônjuge } \\
\hline Categorias & Subcategorias & Categorias & Subcategorias \\
\hline \multirow{4}{*}{$\begin{array}{l}\text { Impacto ao nível da } \\
\text { saúde (11) }\end{array}$} & Ritmo do sono (3) & \multirow{4}{*}{$\begin{array}{l}\text { Impacto ao nível da } \\
\text { saúde (4) }\end{array}$} & A nível psicológico (2) \\
\hline & A nível físico (3) & & A nível físico (1) \\
\hline & Saúde e bem-estar (3) & & Saúde e bem-estar (1) \\
\hline & A nível psicológico (2) & & \\
\hline \multirow{3}{*}{$\begin{array}{l}\text { Impacto na vida } \\
\text { familiar (5) }\end{array}$} & & \multirow{3}{*}{$\begin{array}{l}\text { Impacto na vida } \\
\text { familiar/conjugal } \\
\text { (3) }\end{array}$} & Nível conjugal (1) \\
\hline & Tempo com a família (4) & & Tempo com os filhos (1) \\
\hline & Ausência de rotina (1) & & $\begin{array}{l}\text { Esforço de ajustamento dos filhos } \\
\text { (1) }\end{array}$ \\
\hline $\begin{array}{l}\text { Impacto na vida } \\
\text { social (3) }\end{array}$ & --- & $\begin{array}{l}\text { Impacto a nível } \\
\text { social (1) }\end{array}$ & --- \\
\hline $\begin{array}{l}\text { Motivações } \\
\text { económicas (1) }\end{array}$ & --- & --- & --- \\
\hline Género (1) & Tarefas domésticas (1) & --- & --- \\
\hline
\end{tabular}

\section{DISCUSSÃo}

O presente estudo assumiu como principais objetivos analisar se existiam diferenças do impacto do trabalho por turnos rotativos na vida familiar e social entre os dois membros da díade trabalhador(a) cônjuge e analisar o impacto do trabalho por turnos na díade comparando diferentes horários de trabalho (Rotativo - Rotativo; Rotativo - Normal).

Os resultados, de um modo global, revelaram existir um impacto moderado a elevado na maioria dos itens (em 15 dos 18 domínios avaliados) e relativamente baixo nos restantes três. As áreas apontadas 
como menos afetadas e mais afetadas pelo trabalho por turnos na vida familiar e social são similares nas duas perspetivas (trabalhadores(as) - cônjuges). Neste contexto, destacam-se os itens "Contacto parental entre trabalhador(a) e o(s) seu(s) filho(s) durante a manhã" como o domínio menos afetado pelo impacto do trabalho por turnos, e "Contacto parental entre trabalhador(a) e o(s) seus(s) filho(s) durante a tarde" como o mais afetado. Estes resultados vão de encontro aos resultados de Rapaport e Le Bourdais (2008), onde o impacto do trabalho por turnos no tempo com as crianças parece ser maior aquando do turno da tarde. Este horário mostra-se importante para a interação, pois é o momento em que as crianças chegam a casa da escola (Rapoport \& Le Bourdais, 2008; Volger et al., 1988). No estudo de Prata e Silva (2013), realizado em contexto português, o turno da tarde (quer integrado num sistema rotativo quer fixo) foi o menos bem avaliado do ponto de vista da satisfação com a vida familiar e social. No estudo de Costa e Silva (2019), no entanto, o turno da noite foi o percecionado como o mais prejudicial (seguindo-se-lhe em todo o caso o turno da tarde) na perspetiva dos cônjuges quanto ao impacto do trabalho por turnos na relação trabalhador(a)-criança(s). De facto, se pensarmos nos momentos de interação entre pais e filhos, o final da tarde e os fins de semana parecem ser momentos cruciais ao convívio parental, dado que essas alturas são tradicionalmente os tempos livres dos quais os filhos dispõem e necessitam do acompanhamento parental em atividades escolares (e.g., ajuda nos trabalhos de casa) ou atividades de lazer (e.g., acompanhamento em atividades desportivas aos fins de semana).

A dimensão "Conflito conjugal" foi percecionada como a menos afetada pelo trabalho por turnos, enquanto a "Vida social conjunta" foi percecionada como a mais afetada. Estes resultados são consistentes com os obtidos no estudo de Costa e Silva (2019), onde o impacto do trabalho por turnos no conflito conjugal foi avaliado também como reduzido, contrariando assim os resultados obtidos no estudo de Smith e Folkard (1993b) onde esta área foi das piores avaliadas pelas esposas dos trabalhadores por turnos rotativos. Estas diferenças com o estudo original podem surgir devido a mudanças temporais, culturais e na sociedade que ocorreram entre a realização dos dois estudos. Contudo, a investigação deste domínio é escassa pelo que se torna necessário gerar mais conhecimento de modo a que se possam tirar ilações melhor fundamentadas e atualizadas. No que concerne à vida social conjunta, também Costa e Silva (2019) observaram um impacto negativo elevado no que diz respeito à perspetiva dos cônjuges. Na perspetiva do(a) trabalhador(a), Baker et al. (2003) e Simões et al. (2010) apontam a dificuldade de conciliação do tempo livre comum do trabalhador com a sua família e amigos.

Quando os itens foram agrupados em duas dimensões e foi medido o grau de acordo dentro das díades, os resultados mostram acordo moderado dentro do casal no que diz respeito ao impacto do trabalho por turnos na vida familiar e social. Estes resultados vão de encontro ao estudo de Newey e Hood (2004), onde trabalhador(a) e cônjuge mostraram-se congruentes no que requer ao impacto do trabalho por turnos na vida familiar e social. A vida familiar e social foram as áreas da vida do indivíduo apontadas como as mais afetadas pelo trabalho por turnos, sendo avaliadas de forma mais negativa pelos dois membros do casal comparativamente com outras dimensões - sono, fadiga, saúde e stress. Esta congruência, como referem os próprios autores do estudo, pode advir do facto de muitos dos(as) parceiros(as) serem também eles(as) próprios(as) trabalhadores(as) por turnos, o que deverá ser sustentado em estudos posteriores.

Quanto ao segundo objetivo, analisamos o grau de acordo nas díades tendo em conta o tipo de horário de cada membro do casal, visto que a nossa amostra de cônjuges é composta por um terço de pessoas a laborar por turnos rotativos. Dividimos a análise sobre o impacto do trabalho por turnos em casais em que ambos os membros trabalhavam por turnos rotativos ou em que apenas um dos membros trabalha por turnos rotativos (trabalhador) e o outro trabalha em horário normal (cônjuge). Os resultados revelaram uma diferença marginalmente significativa entre os dois grupos, do ponto de vista do trabalhador, no que diz respeito ao impacto do trabalho por turnos na "Vida de Casal". Trabalhadores do grupo com horário rotativo-rotativo avaliaram de forma mais negativa este item. Embora não possa ser feita uma relação direta, o estudo de Shen e Dicker (2008) (em que só avaliava a perceção do trabalhador) aponta o impacto negativo gerado pelo trabalho por turnos rotativos no relacionamento conjugal. Esta modalidade horária, na perspetiva dos trabalhadores, colocava os relacionamentos sob stress. No que respeita às análises das correlações entre os dois grupos de díades, das correlações entre o ponto de vista do cônjuge e o ponto de vista do trabalhador, no grupo rotativo-rotativo esta correlação mostrou-se significativamente mais baixa do que no grupo rotativo-normal na dimensão "Vida de Casal". Como refere Iskra-Golec et al. (2016), quando os dois membros do casal são trabalhadores por turnos o impacto do trabalho por turnos tem um efeito mais negativo nas relações conjugais. Também Newey e Hood (2004) observaram que os parceiros, que eram eles próprios trabalhadores por turnos, relataram uma perturbação pessoal semelhante à experiência do próprio trabalhador por turnos; por outro lado, os cônjuges que não trabalhavam numa modalidade horária similar, relatavam uma perturbação pessoal significativamente menor relativamente ao impacto do trabalho por turnos. Estas diferenças podem 
refletir as dificuldades de manter um relacionamento e estilo de vida congruentes com os dois horários rotativos do casal (Newey \& Hood, 2004).

Quanto à comparação de perspetivas nas questões abertas, foi possível constatar também a congruência entre trabalhadores(as) - cônjuges nas duas questões (opinião dos participantes acerca do contacto insuficiente entre os(as) trabalhadores(as) - crianças; comentários sobre o impacto do horário de trabalho dos(as) trabalhadores(as)). Foi observado na primeira questão, pelos participantes que identificaram o contacto como insuficiente, um maior impacto do trabalho por turnos rotativos nas categorias "Acompanhar desenvolvimento das crianças" (subcategorias: escolar; atividades de lazer) e "Disponibilidade para comunicação/interação familiar" (subcategorias: turno da tarde; interação aos fins de semana) nas duas perspetivas. Estes resultados são consistentes com a literatura (e.g., Li et al., 2014; Lourenço et al., 2008; Rapoport \& Le Bourdais, 2008) que referem que esta modalidade horária pode ser prejudicial para as crianças, quer a nível de acompanhamento do desenvolvimento (e.g., a nível escolar) quer a nível de interação/comunicação - ter tempo para dedicar à família (e.g., finais de tarde livres que é quando os filhos chegam da escola e fins de semana). Relativamente aos comentários da experiência do trabalho por turnos, tanto os(as) trabalhadores(as) como os cônjuges percecionaram o horário rotativo como causador de impacto negativo a nível da saúde e familiar, havendo diferenças apenas a nível das subcategorias apresentadas por cada grupo. De um modo global, os resultados obtidos são também consistentes com a literatura (e.g., Newey \& Hood, 2004; Simões et al., 2010).

Em jeito de conclusão, os resultados obtidos no nosso estudo são consistentes com estudos anteriores (e.g., Costa \& Silva, 2019; Iskra-Golec et al.,2016; Li et al., 2014) em que se encontram evidências do impacto negativo do trabalho por turnos na vida familiar e social, tanto a nível parental como conjugal ou, ainda, a nível social. Estas consequências parecem advir, em grande parte, da dessincronização dos trabalhadores com os restantes membros do seu agregado familiar e amigos, dado que em momentos temporais importantes como os finais de tarde e os fins de semana os trabalhadores por turnos estão a trabalhar. Contudo, este estudo abordou uma perspetiva pouco explorada na literatura ao comparar a perspetiva dos trabalhadores com a perspetiva dos(as) seus/suas cônjuges/companheiros(as) e obteve resultados similares a estudos que apenas abordaram a perspetiva dos(as) trabalhadores(as). 0 que pode significar que não são apenas os(as) próprios(as) trabalhadores(as) por turnos que percecionam os impactos e são afetados pelo horário de trabalho que praticam, mas também os(as) seus/suas cônjuges/companheiros(as). Neste sentido, é importante continuar os estudos sobre esta temática e encontrar estratégias de intervenção que ajudem a minimizar o conflito trabalho-família suscitado por este regime horário.

$\mathrm{Na}$ interpretação dos resultados, devem ter-se em conta algumas limitações. Em primeiro lugar, a recolha ser concentrada apenas numa empresa do setor industrial, não podendo haver generalização dos resultados. Em segundo lugar, este estudo debruça-se sobre um tipo específico de rotação de trabalho por turnos, não incluindo aqui a análise do impacto do trabalho por turnos a nível familiar e social de outros sistemas de rotação de trabalho por turnos (e.g., rotação rápida). Para tentar ultrapassar as limitações referidas, sugere-se o alargamento do estudo a outras empresas que laborem também em regime de turnos e a diferentes configurações de sistemas de turnos. Em terceiro lugar, o número de participantes ser relativamente reduzido dentro de cada grupo (trabalhador(a) - cônjuge), o que não nos permitiu análises mais específicas (e.g., diferenças de género e diferenças entre casais com filhos e sem filhos na díade), sugerindo igualmente possibilidades de aprofundamento nesta área. Além da integração da perspetiva dos cônjuges na compreensão dos efeitos do trabalho por turnos - bastante escassa na literatura - outra possibilidade aprofundamento da compreensão da temática seria a de alargar a perceção de tais efeitos na perspetiva dos filhos(as) de trabalhadores(as) por turnos.

\section{REFERÊNCIAS}

Baker, A., Ferguson, S., \& Dawson, D. (2003). The perceived value of time. Time \& Society, 12(1), 27-39. https://doi.org/10.1177/0961463X03012001444

Bardin, L. (2009). Análise de conteúdo. Edições 70.

Costa, D. (2016). Trabalho por turnos e vida familiar e social: A perspetiva dos familiares (Dissertação de Mestrado não publicada). Escola de Psicologia, Universidade do Minho, Braga

Costa, D., \& Silva, I. S. (2019). Social and family life impact of shift work from the perspective of family members. Revista de Administração de Empresas, 59(2), 108-120. https://doi.org/10.1590/s0034759020190204

Costa, G. (1997). The problem: Shiftwork. Chronobiology International, 14(2), 89-98. https://doi.org/10.3109/07420529709001147

Costa, G. (2003). Shift work and occupational medicine: An overview. Occupational Medicine, 53(2), 8388. https://doi.org/10.1093/occmed/kqg045 
Costa, G., Åkerstedt, T., Nachreiner, F., Baltieri, F., Carvalhais, J., Folkard, S., Dresen, M. F., Gadbois, C., Gartner, J., Sukalo, H. G., Härmä, M., Kandolin, I., Sartori, S., \& Silvério, J. (2004). Flexible working hours, health, and well-being in Europe: Some considerations from a SALTSA project. Chronobiology International, 21(6), 831-844. https://doi.org/10.1081/CBI-200035935

Craig, L., \& Brown, J. E. (2014). Weekend work and leisure time with family and friends: Who misses out? Journal of Marriage and Family, 76(4), 710-727. https://doi.org/10.1111/jomf.12127

Demerouti, E., Geurts, S. A. E., Bakker, A. B., \& Euwema, M. (2004). The impact of shiftwork on work-home conflict, job attitudes and health. Ergonomics, 47(9), 987-1002. https://doi.org/10.1080/00140130410001670408

Dhande, K. K., \& Sharma, S. (2011). Influence of shift work in process industry on workers' occupational health, productivity, and family and social life: An ergonomic approach. Human Factors and Ergonomics in Manufacturing, 21(3), 260-268. https://doi.org/10.1002/hfm

Eurofound. (2016). European Working Conditions Survey - Overview report. Office of the European Union. Luxembourg. https://doi.org/10.2806/518312

Field, A. P. (2013). Discovering statistics using IBM SPSS Statistics: And sex and drugs and rock ' $n$ ' roll $\left(4^{\text {th }}\right.$ ed.). Sage

Greenwood, K. (1983). A report on the SECV quality of life of shiftworkers survey 1982. Asia Pacific Journal of Human Resources, 21(4), 35-39. https://doi.org/10.1177/103841118302100410

Handy, J. (2010). Maintaining family life under shiftwork schedules: A case study of a New Zealand petrochemical plant. New Zealand Journal of Psychology, 39(1), 29-37.

Hossain, J. L., \& Shapiro, C. M. (1999). Considerations and possible consequences of shift work. Journal of Psychosomatic Research, 47(4), 293-296. https://doi.org/10.1016/S0022-3999(99)00073-2

Iskra-Golec, I., Barnes-Farrell, J., \& Bohle, P. (Eds.) (2016). Social and Family Issues in Shift Work and Non Standard Working Hours. Springer International Publishing. https://doi.org/10.1007/978-3-31942286-2

Iskra-Golec, I., Smith, L., Wilczek-Rużyczka, E., Siemiginowska, P., \& Wątroba, J. (2017). Shift schedule, work-family relationships, marital communication, job satisfaction and health among transport service shift workers. International Journal of Occupational Medicine and Environmental Health, 30(1), 121-131. https://doi.org/10.13075/ijomeh.1896.00670

Kenny, D. A., Kashy, D. A., \& Cook, W. L. (2006). Dyadic data analysis. Guilford.

Li, J., Johnson, S. E., Han, W. J., Andrews, S., Kendall, G., Strazdins, L., \& Dockery, A. (2014). Parents' nonstandard work schedules and child well-being: A critical review of the literature. Journal of Primary Prevention, 35(1), 53-73. https://doi.org/10.1007/s10935-013-0318-z

Lourenço, R. A. P., Ramos, S. I. V., \& Cruz, A. G. (2008). Implicações do trabalho por turnos na vida familiar de enfermeiros: Vivência dos parceiros. http://www.psicologia.pt/artigos/textos/A0417.pdf

Martins, P., \& Martins, A. (1999). O regime de horário de trabalho e a vida social e doméstica: Satisfação e estratégias de coping - Um estudo numa amostra de enfermeiros. Análise Psicológica, 17(3), 529546. http://search.proquest.com/docview/619440822?accountid=17225

Monk, T., Folkard, S., \& Wedderburn, A. (1996). Maintaining safety and high performance on shiftwork. Applied Ergonomics, 27(1), 17-23.

Myers, L., \& Sirois, M. J. (2014). Spearman Correlation Coefficients, Differences between. In Wiley StatsRef: Statistics Reference Online. John Wiley \& Sons, Ltd. https://doi.org/10.1002/9781118445112.stat02802

Newey, C. A., \& Hood, B. M. (2004). Determinants of shift-work adjustment for nursing staff: The critical experience of partners. Journal of Professional Nursing, 20(3), 187-195. https://doi.org/10.1016/j.profnurs.2004.04.007

Perrucci, R., MacDermid, S., King, E., Tang, C.-Y., Brimeyer, T., Ramadoss, K., Kiser, S. J., \& Swanberg, J. E. (2007). The significance of shift work: Current status and future directions. Journal of Family \& Economic Issues, 28(4), 600-617. https://doi.org/10.1007/s10834-007-9078-3

Prata, J., \& Silva, I. (2013). Efeitos do trabalho em turnos na saúde e em dimensões do contexto social e organizacional: Um estudo na indústria eletrônica. Revista Psicologia: Organizações e Trabalho, 13(2), 141-154.

Presser, H. B. (1994). Employment schedules among dual-earner spouses and the division of household labor by gender. American Sociological Review, 59(3), 348-364. https://doi.org/10.2307/2095938

Rapoport, B., \& Le Bourdais, C. (2008). Parental time and working schedules. Journal of Population Economics, 21(4), 903-932. https://doi.org/10.1007/s00148-007-0147-6

Shen, J., \& Dicker, B. (2008). The impacts of shiftwork on employees. The International Journal of Human Resource Management, 19(2), 392-405. https://doi.org/10.1080/09585190701799978 
Silva, I. (2012). As condições de trabalho no trabalho por turnos: Conceitos, efeitos e intervenções. Climepsi Editores.

Silva, I., Prata, J., Ferreira, A., \& Veloso, A. (2014). Shiftwork experience: Worker's vision of its impacts. In P. Arezes et al. (Eds.), Occupational Safety and Hygiene II (pp. 651-656). Taylor \& Francis Group.

Simões, M., Marques, F., \& Rocha, A. (2010). 0 trabalho em turnos alternados e seus efeitos no cotidiano do trabalhador no beneficiamento de grãos. Revista Latino-Americana de Enfermagem, 18(6), 1070-1075. https://doi.org/10.1590/S0104-11692010000600005

Smith, L., \& Folkard, S. (1993a). The impact of shiftwork on personnel at a nuclear power plant: An exploratory survey study. Work and Stress, 7(4), 341-350. https://doi.org/10.1080/02678379308257073

Smith, L., \& Folkard, S. (1993b). The perceptions and feelings of shitwokers partners. Ergonomics, 36(13), 299-305. https://doi.org/10.1080/00140139308967885

Strazdins, L., Korda, R., Lim, L., Broom, D., \& D'Souza, R. (2004). Around-the-clock: Parent work schedules and children's well-being in a 24-h economy. Social Science and Medicine, 59(7), 1517-1527. https://doi.org/10.1016/j.socscimed.2004.01.022

Tuttle, R., \& Garr, M. (2012). Shift work and work to family fit: Does schedule control matter? Journal of Family and Economic Issues, 33(3), 261-271. https://doi.org/10.1007/s10834-012-9283-6

Volger, A., Ernst, G., Nachreiner, F., \& Hänecke, K. (1988). Common free time of family members under different shift systems. Applied Ergonomics, 19(3), 213-218. https://doi.org/10.1016/00036870(88)90139-1

Wilson, M. G., Polzer-Debruyne, A., Chen, S., \& Fernandes, S. (2007). Shift work interventions for reduced $\begin{array}{lllll}\text { work-family } \quad \text { conflict. } & \text { Employee }\end{array}$ https://doi.org/10.1108/01425450710719996

Historial do artigo

Recebido 03/2019

Aceite $\quad 07 / 2020$

Publicado 08/2020 